\title{
Students’ Choice of Major and Future Occupations: Implications for Education Policy
}

\author{
Flora M. Díaz-Pérez, Olga González-Morales \\ Universidad de La Laguna, La Laguna, Spain \\ Email: fdiazp@ull.es, olgonzal@ull.es
}

Received June 5, 2012; revised August 5, 2012; accepted August 13, 2012

\begin{abstract}
The factors that determine and influence the choices made by male and female students with regard to their studies and future occupations need to be taken into account in decisions concerning the targeting of human capital investment and the type of policies to be implemented in order to facilitate the transition of young people to working life. In the present study we consider the role played by gender, individual career aspirations and school characteristics in young people's subject choice in the education system of the Canary Islands (Spain). Specifically, the results indicate that, as a rule, Humanities are chosen by female students who hope to obtain employment in a subordinate post and who study in nonurban public schools in which the careers teacher is not part of the management team. In the other hand, Science \& Technology are chosen by men who study in urban private schools in which the careers teacher is part of the management team, and their main occupational aspiration is a managerial position.
\end{abstract}

Keywords: Young People; Working Life; Gender; Individual Career Aspirations; School Characteristics; Managerial Position

\section{Introduction}

Understanding the factors that determine and influence the choices male and female students make with regard to their studies and future occupations plays a crucial part in the explanation of earnings levels, from both the social and individual perspectives. These factors need to be taken into account therefore in decisions concerning the targeting of human capital investment and the type of policies to be implemented to facilitate the transition of young people to working life [1]. In the present study we consider the role played by the type of school-i.e. whether it is public (state-run) or private- in young people's subject choice in the education system of the Canary Islands (Spain).

Spain's current education system is the product of the legislative reforms introduced by the Education Law of 3 October 1990 (known by its acronym LOGSE) ${ }^{1}$, which adapted education and training objectives to the new European Union guidelines. Secondary education in Spain covers compulsory secondary education $(\mathrm{ESO})^{2}, \mathrm{Ba}$ -

\footnotetext{
*The present study was supported financially by the "Instituto Canario de la Mujer (Canarian Government)", and some empirical results were shown on O. González-Morales Doctoral Thesis.

${ }^{1}$ Official State Journal (BOE), No. 238, 4 October 1990.

${ }^{2}$ This stage (12 - 16 years) completes basic schooling and is divided into two cycles, each lasting two years.

${ }^{3}$ Begins at 16 and is divided into two years.
}

Chillerato $^{3}$ (Baccalaureate) and the early stage of vocational training. Careers Guidance departments play a key role in the system in helping students decide which studies to pursue [2], particularly when they progress from one level or cycle to another and have to choose the pathway best suited to their personal characteristics and career interests.

For the above reasons we have focused our study on the evaluation, from the perspective of career guidance teachers, of the potential influence of gender, individual career aspirations and school characteristics on students' choice of Baccalaureate pathways ("majors").

The choice of major has been studied using a number of different approaches, two of the most common being studies which focus on the differences in choices made by men and women and, secondly, those aimed at identifying the decisive role played by the type of school. This paper incorporates both approaches, while also including other variables such as students' career aspirations, the type of studies they hope to follow, and the geographical location of the school.

An important feature of the present study is that the methodology includes a new element, namely, interviews with careers guidance teachers in schools to ascertain student preferences with respect to their studies and future employment. The opinion of careers guidance teach- 
ers has been considered for two reasons ${ }^{4}$.

1) It is part of their job to be aware of the wishes and professional aspirations of the students in their school.

2) Another important aspect of their role is to advise students on appropriate subject choice, based on students' occupational aspirations and the labour market situation.

Virtually all the studies carried out accept that differences in the choice of subject pathways at school underlie inequalities in the future employment situations of college graduates, and also that female wages are significantly lower than those of males, even after controlling for differences in college major and job characteristics [3]. Hence, the failure to choose subjects giving access to better-paid jobs bears a higher future cost in labour terms for females, given that market reality shows that, under equal conditions, men always earn more.

Furthermore, in the study presented here we show that differences in the choice of major are, both for men and women, heavily determined by the type of school (public or private). The findings set out in this paper indicate that differences between the labour market situation of men and women cannot be explained on the basis of academic results alone. In other words, even if women choose intensive study of mathematics, which would normally produce higher earnings on the market, empirical evidence shows that they generally occupy a lower rung in the jobs' hierarchy and therefore earn less than men [4, $5]$.

\section{Background}

\subsection{Male-Female Labour Market Inequalities}

Available statistical data corroborate the continued existence of a considerable wage gap separating men and women. The causes of this gap have not been accounted for fully. The most common economic explanations fall into three categories: the human capital theory, discrimination and the concentration of women in certain occupations. The human capital explanation is unsupported by the data: gender differences in experience, education level and employment background account for a mere one-third of wage differences between men and women [6]. Moreover, although women are very much crowded into relatively few occupations, this circumstance in itself does not explain how and why it comes about.

Reference [6] note that women earn less than men even if they hold similar qualifications and the gap is due to the effects of discrimination and socialization. The authors hold that socialization and discrimination operate jointly and concurrently and add further that, at key decision moments, such as the choice of major, the factors

${ }^{4}$ Official Journal of the Canaries (BOC) (1995): Decree 23/1995, 24 February, regulating guidance in schools in the Canary Islands. BOC, 20 March 1995. acting on such decisions need to be investigated in detail.

Reference [7] shows that the "expected earnings" variable is essential in the choice of major at college. There are, however, significant differences in the impact of expected earnings according to gender. In choosing an occupation, individuals are less influenced by initial earnings levels and more influenced by the stream of earnings that the occupations are expected to yield. Students are motivated in their choice of major by the possibility of access to higher earnings streams. Hence, an analysis of the impact of the perceived probabilities of success for a given college major at the time of choice can have important education policy implications. Choosing a major is a decision made under conditions of uncertainty, to the extent that one must successfully complete the major to access the associated earnings.

However, one may wonder why there are such marked gender-based differences in major choice. [7], for instance, find that gender correlates highly with the choice of "science" major. A male student is significantly more likely to choose science ahead of education. [8], for their part, note that student choice of field is consistent with an earnings-maximization or utility-maximization view of field choice. Thus, if we wish to increase the proportion of women in sciences, we need to do something to change the underlying mathematical-attribute distribution. In this regard, [8] states that "women are lower paid because the human capital in these fields can be produced with less of an important scarce attribute (quantitative ability)".

However, $[9,10]$ find that "even after extensive control for gender differences in age, education (both level and field), sector industry, and occupation, the glass ceiling effect found in the raw data persists to a considerable extent". To the outcome obtained by $[9,10]$ the present study incorporates a new element, namely, the decisive role played by school type in decisions taken by male and female students with respect to their course of study.

\subsection{Type of School}

References $[3,11]$ have already considered the role of the school in the major choice of male and female graduates. Their findings on college majors are consistent with studies that have examined differences in initial and later earnings of graduates with different majors [12-15]. With respect to college quality, they found that males obtained an earnings advantage for attending a private school, but females did not.

Various models demonstrate the effects on the quality of public education of the presence of private schools in a given area [16-19]. Specifically, with regard to how school districts modify their behaviour in response to increased competition, evidence exists that high levels of competition encourage them to allocate a greater propor- 
tion of resources to the classroom [17,20].

Similarly, [18] have examined the relationship between private school enrolments and public school performance, finding that educational achievement in public schools is higher in localities where a larger percentage of school-age children are enrolled in private schools. The authors conclude that, faced with market competetion, public schools may respond by improving the quality of the education delivered.

According to a theoretical model developed by [21], the relative size of the private sector in education is determined by the following:

1) Excess demand;

2) The existence of heterogeneous demands (due to deep-seated religious and linguistic differences);

3) The supply of non-profit firms in the society concerned.

References [20,22] analyse the possible relationship between the quality of public schools and competition from private schools and conclude that public school quality significantly impacts on students and on the demand for private schools. The results presented in [22] indicate that exogenous variation in competition from private schools does appear to improve the quality of public schools. More specifically, increased competition from private schools leads to higher graduation rates in public schools. However, the main finding of Dee's study is that the demand for private schools and the quality of public schools are simultaneously determined.

\subsection{Variables Allowing Public Education to Be Measured: The Role of Sociological Factors}

Approaches differ also as to which specific variables should be used to measure quality in public education and also with respect to the components of the supply and demand function in public education. In this section we follow the approach found in the literature on the subject, focusing in particular on the role of sociological variables.

Many studies have shown how demand for private schools is significantly affected by socio-economic status [23-28]. Other studies indicate that socio-economic characteristics strongly correlate with the level of student achievement $[29,30]$.

According to [30], public school quality can be measured using two approaches: the value-added approach and the levels of proficiency test outcomes. The latter, argues Brasington, should be accepted in education literature and should also be valued in the housing market [31]. Reference [32], for example, find that the value-added of achievement in mathematics is positively related to house prices in the Northern Dallas sub-market, but not significantly related to prices in the less-prosperous Southern
Dallas sub-market.

Reference [3] estimate the economic returns to college and include various dimensions of college quality, major and performance. They examine gender differences and consider the following school level variables: a dummy variable to indicate private school, variables indicating the social composition of students, two measures of attractiveness and exclusiveness, indicators of available resources, indicators of the orientation and atmosphere of the school.

\subsection{Tiebout Endogeneity}

As far back as the 1950s, however, [33] had noted the importance of allocating public funding not on the basis of market criteria but simply in accordance with the preferences of the population. According to Tiebout, “... no 'market type' solution exists to determine the level of expenditures on public goods. Seemingly, we are faced with the problem of having a rather large portion of our national income allocated in a 'non-optimal' way when compared with the private sector" (p. 416)... "Those who are tempted to compare this model with the competetive private model may be disappointed. Those who compare the reality described by this model with the reality of the competitive model may find that local government represents a sector where the allocation of public goods (as a reflection of the preferences of the population) need not take a back seat to the private sector" (p. 424).

Reference [16] obtained empirical results suggesting that two types of endogeneity exist. In the first, the endogeneity is unexpected, i.e. to the extent that parents assume that they make sectoral decisions with respect to schools (thus impacting on the private school enrolment rate) in part based on the quality of the district's public schools (proxied here by public school expenditure per pupil); in turn, the public school enrolment rate affects public school expenditure per pupil via the voting mechanism.

The second potential source of endogeneity, Tiebout endogeneity, may arise if unobservable community preferences correlate with both public school expenditure and private school enrolment. The empirical results appear quite sensitive to model specification and point to the existence of both types of endogeneity. In other words, they suggest that unobservable preferences of the population correlate, in parallel, with public expenditure on education and private school enrolments.

\section{Methodology and Initial Hypotheses}

\subsection{Variables}

The variables considered in the analysis and its categories are as follows: 


\begin{tabular}{|c|c|c|c|c|}
\hline Variables & & Categories & & \\
\hline Gender & Female & Male & & \\
\hline Type of School & Public & Private & & \\
\hline Employment & Employed & Self-Employed & & \\
\hline Type of Job & Managerial & Subordinate & & \\
\hline Zone & Provincial Capital & North & South & Small Islands \\
\hline Future Studies & Compulsory Secondary & Baccalaureate or Vocational Training & University & \\
\hline Careers Teacher on Management Team & Yes & No & & \\
\hline
\end{tabular}

\subsection{Sampling Procedure}

A representative selection of the range of secondary schools in the Canary Islands region of Spain was taken for our empirical study. The schools were selected from the total of 396 making up the school population that year on the seven islands. Interviews were conducted during 2002.

Sampling took into account the difference in the number of public and private schools between the region's two provinces (Santa Cruz de Tenerife and Las Palmas de Gran Canaria).

Proportionate stratified sampling was used, with each strata represented by the school type and area. We began by carrying out simple random sampling to enable us to calculate the sample size and then allocated the proportions, i.e. distribution of the sample among the strata proportionately to size to ensure they were representative of schools in the population segment studied.

The choice of school was entirely random, respecting the proportion of each strata. The sample finally comprised 248 schools.

The maximum estimation error for the total sample, following the interviews with the careers teachers, was $\pm 4.1 \%$, with $95.5 \%$ reliability.

The pathways of Spain's Bachillerato ${ }^{5}$ (Baccalaureate) were grouped into two knowledge areas: Natural Sciences, Health Sciences and Technology, which were considered jointly under the broad category of "science and technology", and a second broad group comprising the Arts, Social Sciences and Humanities, which we have denoted collectively "social sciences and the humanities".

As regards the general characteristics of the sample, $50 \%$ of the people interviewed were aged $35-44$ and $60 \%$ were women. $44 \%$ of the interviews were conducted with careers guidance teachers, $22 \%$ with school princepals, $29 \%$ with heads of studies, and the remaining $5 \%$ with other members of staff at the schools. It is worth noting that only $21.4 \%$ of the careers teachers were part of the management team in their school.

Table 1 presents the descriptive analysis of the explanatory variables used to estimate the likelihood that a student will choose a Social Sciences and Humanities pathway.
Table 1. Descriptive analysis of the sample.

\begin{tabular}{|c|c|c|}
\hline Variables & $\begin{array}{l}\text { Science and } \\
\text { Technology }\end{array}$ & $\begin{array}{l}\text { Social Sciences } \\
\text { and Humanities }\end{array}$ \\
\hline \multicolumn{3}{|c|}{ Gender } \\
\hline Female & 37.9 & 90.2 \\
\hline Male & 62.1 & 9.8 \\
\hline \multicolumn{3}{|c|}{ Type of School } \\
\hline Public & 49.2 & 79.4 \\
\hline Private & 50.8 & 20.6 \\
\hline \multicolumn{3}{|c|}{ Employment } \\
\hline Employed & 47.5 & 61.4 \\
\hline Self-Employed & 52.5 & 38.6 \\
\hline \multicolumn{3}{|c|}{ Type of Job } \\
\hline Managerial & 50.8 & 18.5 \\
\hline Subordinate & 49.2 & 81.5 \\
\hline \multicolumn{3}{|c|}{ Zone } \\
\hline Provincial Capital & 47.5 & 30.2 \\
\hline North & 18.6 & 25.9 \\
\hline South & 22.0 & 20.6 \\
\hline Small Islands & 11.9 & 23.3 \\
\hline \multicolumn{3}{|c|}{ Future Studies } \\
\hline Compulsory Secondary & 20.3 & 20.6 \\
\hline Baccalaureate or Vocational Training & 22.1 & 36.5 \\
\hline University & 57.6 & 42.9 \\
\hline \multicolumn{3}{|c|}{ Careers Teacher on Management Team } \\
\hline Yes & 30.5 & 18.0 \\
\hline No & 69.5 & 82.0 \\
\hline
\end{tabular}

Analysis of students choosing the Sciences and Technology pathway indicates that more males $(62.1 \%)$ opt for this type of subject. They tend largely to be male students from schools in the two provincial capitals $(47.5 \%)$, who intend to study at university $(57.6 \%)$ and are from schools where the careers guidance teacher is not part of the school management team (69.5\%).

As regards the Social Sciences and Humanities pathway, the main characteristics emerging from Table 1 are as follows: the pathway is chosen mainly by female students $(90.2 \%)$ studying in public schools $(79.4 \%)$, who aspire to employment $(61.4 \%)$ as opposed to self-employment, in a subordinate post $(81.5 \%)$ and hope to

${ }^{5}$ Royal Decree 1179/1992, 2 October, regulates the minimum requirements for the four "Bachillerato" pathways: Humanities and Social Sciences, Arts, Technology, and Natural and Health Sciences. Official State Journal (BOE), No. 147, 21 October 1992. 
continue their schooling to Baccalaureate level, vocational training or even university. Lastly, the careers guidance teacher is not part of the school management team in a percentage of $82 \%$.

\subsection{Initial Hypotheses}

From the above data it can be seen that student choice of a given pathway (science and technology or social sciences and humanities) appears to depend on certain factors, including gender, school type, student aspirations concerning future studies and occupations, and/or the guidance received at school.

In order to ascertain if a link exists between the dependent variable (subject pathway) and the independent variables and-if it does - to measure the extent of the link and estimate it in terms of the correlation or association of a given choice, we will use logistic regression (logit model), which allows qualitative variables to be included among the predictive variables and dichotomic phenomena to be analysed [34].

In this case, the dependent variable takes the dichotomic form science-technology pathway and social sciences-humanities pathway and since the independent variables precede the event in time the relationship is explained in terms of prediction or determination and the variables can be considered "risk factors".

$$
\operatorname{Ln}\left(p_{2 i} / p_{1 i}\right)=\beta_{1}+\sum \beta_{h} X_{h i} \varepsilon_{i}
$$

$p_{1 i}=$ is 1 if the student chooses science and technology, 0 otherwise;

$p_{2 i}=$ is 1 if the student chooses social sciences and humanities, 0 otherwise;

$X_{h i}=$ value of explanatory variable $h$ for each individual;

$\beta=$ unknown parameters that need to be estimated;

$\varepsilon_{i}=$ term of random disturbance, distributed according to an $\mathrm{N}\left(0, \sigma^{2}\right)$.

Two hypotheses are put forward for the study:

H1: Choice of major in secondary schools is influenced by

1) Gender;

2) The type of school (public-private);

3) The desire to work for others or for self-employment;

4) The type of position aspired to (managerial or subordinate);

5) The location of the school (urban-rural);

6) The participation of careers guidance teacher in the school management team.

H2: The above student decisions-i.e. choice of major-determine the type of post occupied in future and thus account for wage inequalities between men and women.

Consideration of the type of school is a way of characterising and better understanding the influence of the education system on labour market inequalities between men and women. It also affords information for policy makers on how education policy should be directed, depending on whether a school is public or private, in order to correct gender inequalities.

The objectives and hypotheses addressed in this study aim to illustrate that gender inequalities in the labour market are not caused solely by decisions taken by employers and by workers when they finish their education and enter employment. Decisions taken by students during secondary schooling condition their future position on the market.

\subsection{Results}

Overall, the logit model achieves a $78.6 \%$ successful prediction rate, which indicates that the model is good for the future classifications. Specifically, it predicts $93.1 \%$ of Social Sciences pathway cases, and we will therefore focus on this group here.

Analysis of the estimations reveals that males are less likely than females to choose Social Sciences and $\mathrm{Hu}-$ manities. The type of school also conditions the choice of this pathway, which is less likely among students at private schools (see Table 2).

As far as the type of employment and type of position are concerned, there is less likelihood that students choosing the pathway will want to set up as self-employed or aspire to a managerial position.

Regarding intended future studies, it can be seen that students preferring Social Science and Humanities are less likely to go to university.

Geographical location exerts a relatively significant influence on the choice of this pathway. Students from schools in the capitals of both provinces are less likely to follow the pathway, in contrast to those who attend schools on the smaller islands.

Table 2. Logit estimation of the likelihood of choosing the Social Sciences and Humanities pathway.

\begin{tabular}{ccc}
\hline Variables & Coefficient & Sig. \\
\hline Constant & 1.5660 & $0.032^{* *}$ \\
Male & -2.2923 & $0.000^{* * *}$ \\
& Gender & \\
Private & -0.5981 & $0.003^{* * *}$ \\
& Employment & \\
Self-Employment & -0.8580 & $0.035^{* *}$ \\
Type of Job & \\
Managerial & -0.7630 & $0.002^{* * *}$ \\
& Zone & $0.066^{*}$ \\
Provincial Capital & -0.3490 & 0.110 \\
North & 0.2440 & $0.042^{* *}$ \\
Small Islands & 0.5170 & $0.048^{* *}$ \\
University & Future Studies & \\
Careers Teacher Part of Management Team & \\
Yes & -0.9640 & $0.024^{* *}$ \\
Likelihood Ratio Test & 230.032 & $0.021^{* *}$ \\
\hline
\end{tabular}

${ }^{* * *}$ coefficient significant at $1 \% ;{ }^{* *}$ at $5 \% ;{ }^{*}$ at $10 \%$. 
Lastly, students from schools in which the careers teacher is part of the management team are less likely to choose this pathway.

The above analysis has allowed us to identify the existence of different variables that influence the tendency to choose a given subject pathway or major.

As regards the motives given for the choice of pathway, the main reasons identified by female students in both provinces for their choice were essentially their dislike for the subjects taught on the pathway or their perception that they were very difficult. However, a significant number of students did not respond or could not give a reason (see Figure 1).

The main reasons given by female students for not choosing science and technology coincide with the responses given above in the gender table, although some difference is seen with respect to government-funded private schools (see Table 3).

Let us take the analysis further. Breaking down the percentages enables us to simultaneously compare student preferences according to the type of school and gender. Figure 2 illustrates the differences in the pathway choices of female students in the different types of school, with a probability of $p \leq 0.000$. The results appear to discriminate female students in public schools, where only $19.9 \%$ opt for the science and technology pathway, compared to the much higher figure of $55.4 \%$ in private schools, which is still a long way below the figure for male students.

These differences are not observed in the case of male students and the Chi-square test shows that the frequency distributions fit a model distribution, with a probability of $\mathrm{p} \leq 0.821$.

\section{Conclusions and Recommendations}

The study presented here examines the preferences of secondary school students concerning choice of major.

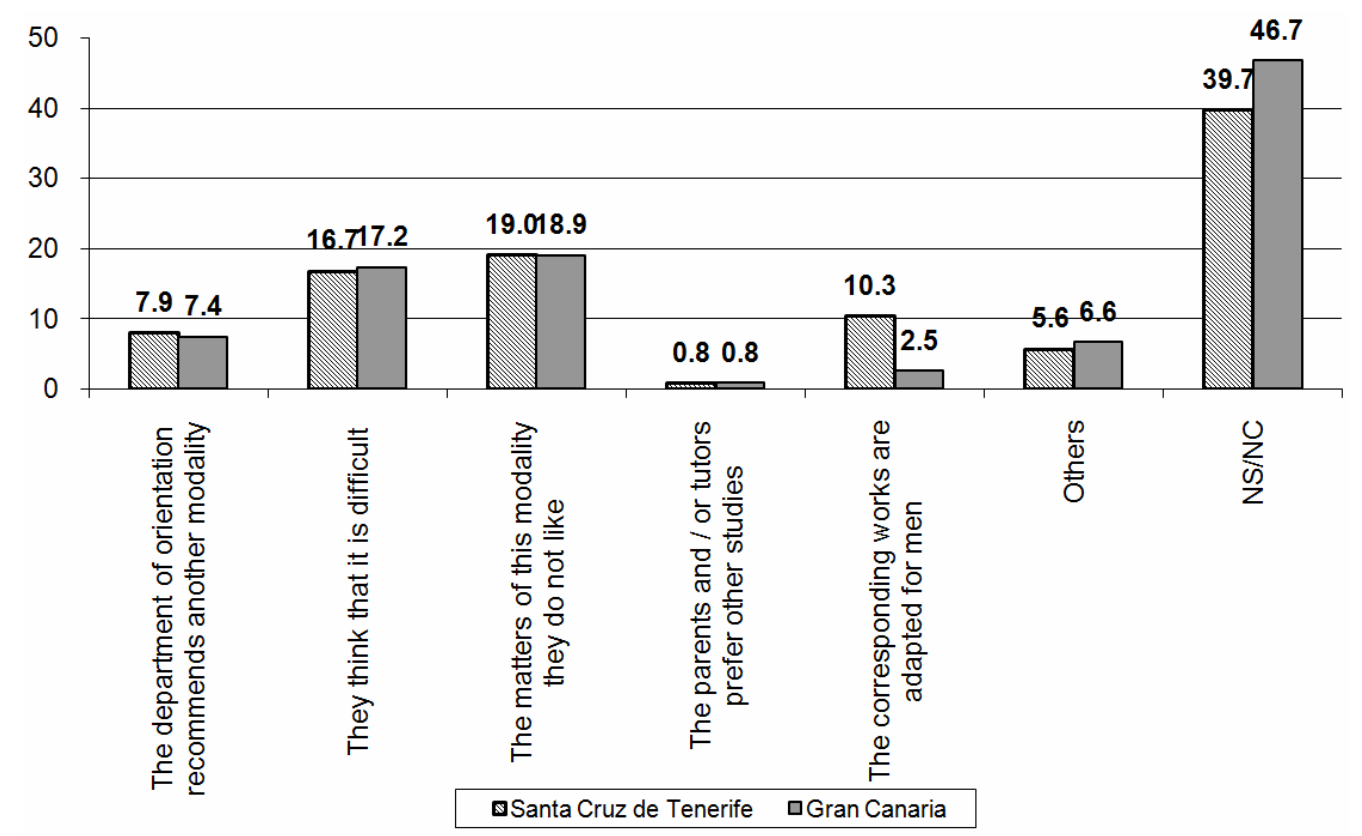

Figure 1. Reasons why females students do not prefer Science-Technology pathway, by province.

Table 3. Reasons why female students choose not to follow the Science-Technology pathway, according to type of school (\%).

\begin{tabular}{cccc}
\hline \multirow{2}{*}{ Reasons } & \multicolumn{3}{c}{ Type of School } \\
\cline { 2 - 4 } & Public & Private, Government-Funded & Fully Private \\
\hline Careers department recommends other pathway & 8.0 & 6.8 & 7.1 \\
Considered difficult & 19.3 & 18.2 & 0.0 \\
Dislike of subjects taught on pathway & 19.9 & 18.2 & 14.3 \\
Parents/guardians prefer other studies & 1.1 & 0.0 & 0.0 \\
The corresponding jobs are appropriate for men & 6.8 & 6.8 & 3.6 \\
Other & 7.4 & 2.3 & 3.6 \\
Do not know/no answer & 37.5 & 47.7 & 71.4 \\
\hline
\end{tabular}




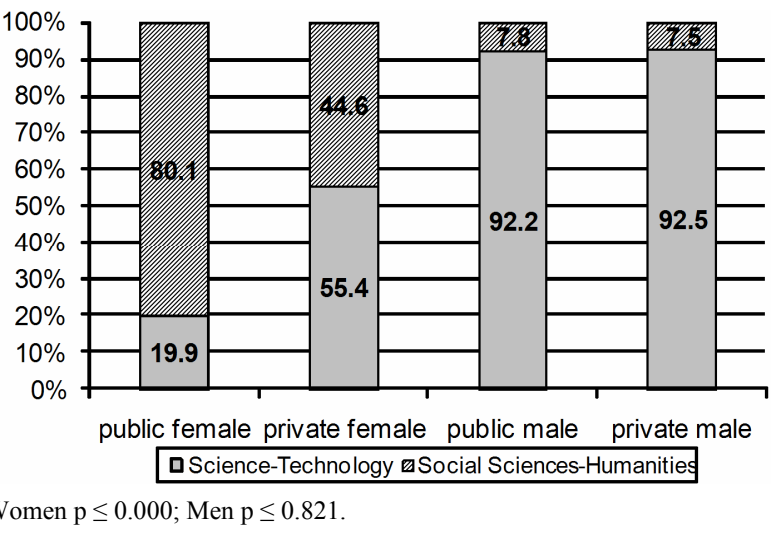

Figure 2. Subject pathway according to school type and gender.

The analysis is based essentially on the gender of the students and the type of school (public or private), although there are other important variables also that influence choice. The results let us to reach some conclusions and recommendations.

\section{Conclusions}

The results obtained show that the choice of the Social Sciences and Humanities pathway is not just genderdependent but is associated also with variables such as the type of school (public or private), the type of employment and post aspired to, the type of studies the student hopes to follow post-Baccalaureate, the location of the school and, lastly, whether or not the careers teacher is part of the school management team. In sum, the results indicate that, as a rule, Humanities are chosen by female students who hope to obtain employment in a subordinate post and who study in non-urban public schools in which the careers teacher is not part of the management team.

Specifically, the opinions of careers teachers with respect to the preferences and aspirations of their students discriminate negatively against females. Furthermore, teachers working in government-funded private schools, and especially those in fully-private schools, consider that their students have higher aspirations concerning their future employment.

Therefore, we can conclude that hypothesis 1 and 2 are fulfilled.

\section{Recommendations}

In the light of prior approaches, the results of our study should serve to redirect education policy rather than to question the efficiency of the allocation of public resources in education.

They should help redefine the role of teachers providing careers guidance in schools, to ensure greater attention is paid to the choices made by students, both male and female, and point them in the direction of studies and careers better geared to favourable labour market conditions.

In this respect, future research should include variables that measure the quality of public schools and the extent to which students are advised to pursue studies and careers offering the best employment possibilities.

The results obtained also underline the need for further studies to complete these findings and take into account the sociological factors explaining why families that send their children to public schools in non-urban zones tend to inculcate - perhaps due to a lack of information, the transmission of cultural values or the children's desire to follow in their parents' footsteps - the wrong choice in their offspring as far as their studies and future careers are concerned.

In sum, education policy needs to be reviewed and integrated with gender policy, and proposals are needed for richer ways for public organizations to study their own gender regimes at secondary schools.

\section{REFERENCES}

[1] OCDE, "Initial Education and the Working Life: To Facilitate the Transition," OCDE, Paris, 2000.

[2] L. Chisholm, "Young Europeans and Guidance: What Do They Need and Want?” CEDEFOP, Salónica, 1996.

[3] R. W. Rumberger and S. Thomas, "The Economic Returns to College Major, Quality and Performance: A Multilevel Analysis of Recent Graduates," Economics of Education Review, Vol. 12, No. 1, 1993, pp. 1-19. doi:10.1016/0272-7757(93)90040-N

[4] F. M. Díaz-Pérez, "Education and Employment Promotion in a Internal Labor Market of the Industrial Sector," EKONOMIAZ (Magazine of Basque Economy), Vol. 22, 1992, pp. 248-267.

[5] F. M. Díaz-Pérez, "Methodology for Determine the Promotion Lines and Ports of Entry of an Industrial Internal Labor Market," International Journal of Manpower, Vol. 14, No. 1, 1993, pp. 40-58. doi:10.1108/01437729310023233

[6] M. E. Corcoran and P. N. Courant, "Sex Role Socialization and Labour Market Outcomes," The American Economic Review, Vol. 75, No. 2, 1985, pp. 275-279.

[7] C. Montmarquette, C. Cannings and S. Mahseredjian, "How Do Young People Choose College Majors?" Economics of Education Review, Vol. 21, No. 6, 2002, pp. 2-17. doi:10.1016/S0272-7757(01)00054-1

[8] M. Paglin and M. Rufolo "Heterogeneous Human Capital, Occupational Choice, and Male-Female Earnings Differences," Journal of Labor Economics, Vol. 8, No. 1, 1990, pp.123-144. doi:10.1086/298239

[9] J. Albrecht, A. Björklund and S. Vroman, "Is There a Glass Ceiling in Sweden," Journal of Labor Economics, Vol. 21, No. 1, 2003, pp. 145-177. doi:10.1086/344126

[10] R. Connell, "Glass Ceilings or Gendered Institutions? 
Mapping the Gender Regimes of Public Sector Worksites," Public Administration Review, Vol. 66, No. 6, 2006, pp. 837-849. doi:10.1111/j.1540-6210.2006.00652.x

[11] O. González Morales, "Analysis of the Business Motivation in the Youth Population According to the Type of Center," Journal of Education, Vol. 331, 2003, pp. 533559.

[12] L. J. Griffin and K. L. Alexander, "Schooling and Socioeconomic Attainments: High School and College Influences," American Journal of Sociology, Vol. 84, No. 2, 1978, pp. 319-347. doi:10.1086/226786

[13] R. W. Rumberger, "The Changing Economic Benefits of College Graduates," Economic Education Review, Vol. 3, No. 1, 1984, pp. 3-11. doi:10.1016/0272-7757(84)90003-7

[14] M. Berger, "Predicted Future Earnings and Choice of College Major," Industrial Labour Relations Review, Vol. 41, 1988, pp. 418-429. doi:10.2307/2523907

[15] E. James, N. Alsalam, J. C. Conaty and D. L. To, "College Quality and Future Earnings: Where Should You Send Your Child to College?" American Economic Review, Vol. 79, No. 2, 1989, pp. 247-252.

[16] D. Goldhaber, "An Endogenous Model of Public School Expenditures and Private School Enrollment," Journal of Urban Economics, Vol. 46, No. 1, 1999, pp. 106-128. doi:10.1006/juec.1998.2115

[17] T. Dee, "Expense Preference and Student Achievement in School Districts," Working Paper, Department of Economics, University of Maryland, College Park, 1997.

[18] J. F. Couch, W. F. Shughart and A. L. Williams, "Private School Enrollment and Public School Performance," Public Choice, Vol. 76, No. 4, 1993, pp. 301-312. doi:10.1007/BF01053301

[19] D. M. Brasington, "Demand and Supply of Public School Quality in Metropolitan Areas: The Role of Private Schools," Journal of Regional Science, Vol. 40, No. 3, 2000, pp. 583-605. doi:10.1111/0022-4146.00189

[20] C. M. Hoxby, "Do Private Schools Provide Competition for Public Schools?” Working Paper No. 4978, National Bureau of Economic Research, Cambridge, 1995.

[21] E. James, "The Public/Private Division of Responsibility for Education: An International Comparison," Economics of Education Review, Vol. 6, No. 1, 1987, pp. 1-14. doi:10.1016/0272-7757(87)90028-8

[22] T. Dee, "Competition and the Quality of Public School,"
Economics of Education Review, Vol. 17, No. 4, 1998, pp. 419-427. doi:10.1016/S0272-7757(97)00040-X

[23] J. M. Gemello and J. Osman, "Estimating the Demand for Private School Enrolment," American Journal of Education, Vol. 92, No. 3, 1984, pp. 262-279. doi:10.1086/443749

[24] J. Martinez-Vázquez and B. Seaman, "Private Schooling and the Tiebout Hypothesis," Public Finance Quartely, Vol. 13, No. 3, 1985, pp. 293-318.

[25] J. E Long and E. F. Toma, "The Determinants of Private School Attendance, 1970-1980," Review of Economics and Statistics, Vol. 70, No. 2, 1988, pp. 351-357. doi:10.2307/1928323

[26] E. West and H. Palsson, "Parental Choice of School Characteristics: Estimation Using State-Wide Data," Economic Inquiry, Vol. 26, No. 4, 1988, pp. 725-740. doi:10.1111/j.1465-7295.1988.tb01525.x

[27] E. Hamilton and M. K. Macauley, "The Determinants and Consequences of Private School Choice," Journal of Urban Economics, Vol. 29, No. 3, 1991, pp. 282-294. doi:10.1016/0094-1190(91)90002-O

[28] H. Lankford and J. Wyckoff, "Primary and Secondary School Choice among Public and Religious Alternative," Economics of Education Review, Vol. 11, No. 4, 1992, pp. 317-337. doi:10.1016/0272-7757(92)90040-A

[29] R. Haveman and B. Wolfe, "The Determinants of Children's Attainment: A Review of Methods and Findings," Journal of Economic Literature, Vol. 33, No. 4, 1995, pp. 1829-1878.

[30] E. Hanushek, "The Economics of Schooling: Production and Efficiency in Public Schools", Journal of Economic Literature, Vol. 24, No. 3, 1986, pp. 1141-1177.

[31] D. M Brasington, "The Supply of Public School Quality," Economics of Education Review, Vol. 22, 2002, pp. 367377. doi:10.1016/S0272-7757(02)00074-2

[32] K. L. Hayes and L. L. Taylor, "Neighborhood School Characteristics: What Signals Quality to Homebuyers," Federal Reserve Bank of Dallas Economic Review, Vol. 3, No. 4, 1996, pp. 2-9.

[33] C. M. Tiebout, "A Pure Theory of Local Expenditure," Journal of Political Economy, Vol. 64, No. 5, 1956, pp. 416-424. doi:10.1086/257839

[34] J. F. Hair, R. E. Anderson, R. L. Tatham and W. C. Black, "Multivariate Data Analysis," Prentice-Hall, Upper Saddle River, 1998. 